\title{
Rabbit Aorta and Human Atherosclerotic Lesions Hydrolyze the Sphingomyelin of Retained Low-density Lipoprotein Proposed Role for Arterial-wall Sphingomyelinase in Subendothelial Retention and Aggregation of Atherogenic Lipoproteins
}

\author{
Scott L. Schissel, ${ }^{\star}$ Judith Tweedie-Hardman, ${ }^{\ddagger}$ Joseph H. Rapp, ${ }^{\S}$ George Graham, ${ }^{\ddagger}$ Kevin Jon Williams, and Ira Tabas ${ }^{\star \Uparrow}$ \\ Departments of*Anatomy \& Cell Biology and "Medicine, and the "College of Physicians \& Surgeons, Columbia University, New York \\ 10032; $\doteqdot$ Department of Surgery, University of California, San Francisco, and the San Francisco Veterans Affairs Medical Center, San \\ Francisco, California 94121; and the ${ }^{\S}$ Dorrance H. Hamilton Research Laboratories, Division of Endocrinology, Diabetes, and Metabolic \\ Diseases, Thomas Jefferson University, Philadelphia, Pennsylvania 19107
}

\begin{abstract}
Aggregation and retention of LDL in the arterial wall are key events in atherogenesis, but the mechanisms in vivo are not known. Previous work from our laboratories has shown that exposure of LDL to bacterial sphingomyelinase (SMase) in vitro leads to the formation of LDL aggregates that can be retained by extracellular matrix and that are able to stimulate macrophage foam cell formation. We now provide evidence that retained LDL is hydrolyzed by an arterial-wall SMase activity. First, we demonstrated that SMase-induced aggregation is caused by an increase in particle ceramide content, even in the presence of excess sphingomyelin (SM). This finding is compatible with previous data showing that lesional LDL is enriched in SM, though its ceramide content has not previously been reported. To address this critical compositional issue, the ceramide content of lesional LDL was assayed and, remarkably, found to be 10-50-fold enriched compared with plasma LDL ceramide. Furthermore, the ceramide was found exclusively in lesional LDL that was aggregated; unaggregated lesional LDL, which accounted for $20-25 \%$ of the lesional material, remained ceramide poor. When $\left[{ }^{3} \mathrm{H}\right] \mathrm{SM}-\mathrm{LDL}$ was incubated with strips of rabbit aorta ex vivo, a portion of the LDL was retained, and the $\left[{ }^{3} \mathrm{H}\right] \mathrm{SM}$ of this portion, but not that of unretained LDL, was hydrolyzed to $\left[{ }^{3} \mathrm{H}\right]$ ceramide by a nonlysosomal arterial hydrolase. In summary, LDL retained in atherosclerotic lesions is acted upon by an arterial-wall SMase, which may participate in LDL aggregation and possibly other SMasemediated processes during atherogenesis. (J. Clin. Invest. 1996. 98:1455-1464.) Key words: atherosclerosis • ceramide - foam cells • phospholipids • hydrolytic enzymes
\end{abstract}

Portions of this study were presented in abstract form at the American Heart Association 67th Scientific Sessions, Dallas, TX, 16 November 1994.

Address correspondence to Ira Tabas, M.D., Ph.D., Department of Medicine, Columbia University, 630 West 168th Street, New York, NY 10032. Phone: 212-305-9430; FAX: 212-305-5052.

Received for publication 28 May 1996 and accepted in revised form 19 July 1996.

J. Clin. Invest.

(C) The American Society for Clinical Investigation, Inc.

0021-9738/96/09/1455/10 \$2.00

Volume 98, Number 6, September 1996, 1455-1464

\section{Introduction}

A key early event in atherogenesis is the subendothelial retention of atherogenic lipoproteins, including $\operatorname{LDL}(1,2)$, lipoprotein(a) $[\mathrm{Lp}(\mathrm{a})]$ (3), and triglyceride-rich lipoproteins (4). Atherosclerosis-susceptible regions of the arterial tree are distinguished by their increased retention of lipoproteins compared with resistant regions $(1,5)$. The retained lipoproteins are likely to trigger a set of biological responses, such as lipoprotein oxidation and endothelial changes $(6,7)$, that are central to the atherogenic process (8).

Lipoproteins retained in the subendothelium are often extensively aggregated $(2,9,10)$. (In our summary of the literature and description of experiments in this paper, we use the term aggregation to designate self-associated LDL due to either adherence of individual particles or fusion.) For example, Hoff et al. (9) and others (10) have shown that LDL extracted from atherosclerotic lesions is aggregated or has an increased tendency to aggregate, whereas plasma LDL exposed to the same extraction procedure as a control does not aggregate. Furthermore, Frank et al. (2) used freeze-etch electron microscopy to demonstrate aggregated LDL in the subendothelium of the rabbit aorta as early as $2 \mathrm{~h}$ after a large bolus injection of human LDL. Subendothelial lipoprotein aggregation is likely to be important in atherogenesis for at least two reasons. First, processes that promote lipoprotein aggregation before or during retention would be expected to increase the amount of material retained (11). Second, aggregated LDL, but not unaggregated LDL, is a potent inducer of macrophage foam cell formation (12-15).

The mechanism of lipoprotein aggregation in lesions is not known. Lipoprotein aggregation can be induced in vitro by vortexing (13), extensive phospholipase C-hydrolysis (14), extensive oxidation (16), and, in work from our laboratories, limited hydrolysis with bacterial sphingomyelinase (SMase) ${ }^{1}$ (15). Vortexing and extensive hydrolysis by phospholipase $\mathrm{C}$ are unlikely to be physiologically important. LDL oxidation does occur in arteries (6), but, as mentioned above, subendothelial LDL aggregates have been shown to be present in normal rabbit aorta as early as $2 \mathrm{~h}$ after an intravenous bolus injection of LDL (2), which may be too soon for substantial LDL oxidation to occur in these normal vessels. The goal of the current study was to test the possible physiological relevance of SMase-induced lipoprotein aggregation. In particular, we

1. Abbreviations used in this paper: PC, phosphatidylcholine; SM, sphingomyelin; SMase, sphingomyelinase. 
show that the mechanism of SMase-induced aggregation of LDL in vitro is entirely consistent with a role for sphingomyelin (SM) hydrolysis in LDL aggregation in vivo, that extracellular, retained LDL extracted from human atherosclerotic lesions shows evidence of having been acted upon by an arterial SMase, and that strips of rabbit aorta ex vivo can hydrolyze the SM of retained LDL. Our results support a role for arterial SMase in LDL aggregation and possibly other SMase-mediated processes during atherogenesis.

\section{Methods}

Materials. sn-1,2-diacylglycerol kinase (from Escherichia coli) was purchased from Calbiochem Corp. (San Diego, CA). Cardiolipin and 1,2-dioleoyl glycerol were purchased from Avanti Polar Lipids (Alabaster, AL). The Superose $6 \mathrm{HR}^{10 / 30}$ gel filtration column was obtained from Pharmacia LKB Biotechnology, Inc. (Piscataway, NJ). $\left[9,10-{ }^{3} \mathrm{H}\right]$ Palmitic acid, $\left[\gamma_{-}{ }^{32} \mathrm{P}\right] \mathrm{ATP}$, and $\mathrm{Na}^{125} \mathrm{I}$ were obtained from DuPont-New England Nuclear (Boston, MA). Tissue culture media, tissue culture reagents, and human recombinant epidermal growth factor were purchased from Life Technologies (Baltimore, MD); fetal bovine serum was from Gemini Bioproducts (Calabasas, CA); and glass tissue culture plates were from Corning Glass Works (Corning, NY). SMase (from Bacillus cereus) and all other reagents were from Sigma Chemical Company (St. Louis, MO). Rabbit anti-human apolipoprotein B-100 polyclonal antiserum was kindly provided by Dr. Henry Ginsberg (Columbia University, New York). Peroxidase-conjugated goat anti-rabbit IgG was purchased from Pierce Chemical Co. (Rockford, IL). Partially purified phospholipid transfer protein was provided by Drs. Xian Chen Jiang and Alan Tall (Columbia University, New York).

Synthesis of $\left[{ }^{3} \mathrm{H}\right] \mathrm{SM}$. [ $N$-palmitoyl-9,10- $\left.{ }^{3} \mathrm{H}\right] \mathrm{SM}$ was synthesized as previously described $(17,18)$. Briefly, $\left[9,10-{ }^{3} \mathrm{H}\right]$ palmitic acid $(25$ $\mathrm{mCi}, 450 \mathrm{nmol}$ ) was stirred for $12 \mathrm{~h}$ at room temperature with an equimolar equivalent of $(N)$-hydroxysuccinimide and with 3-molar equivalents of 1,3-dicyclohexylcarbodiimide in $(N, N)$-dimethylformamide. The reaction was run under dry argon in the dark. Sphingosylphosphorylcholine $(300 \mathrm{nmol})$ and $(N, N)$-diisopropylethylamine $(10 \mu \mathrm{l})$ were then added and the reaction was stirred another $12 \mathrm{~h}$ at room temperature. The reaction was stopped by evaporating the $(N, N)$-dimethylformamide under a stream of $\mathrm{N}_{2}$. [ $N$-palmitoyl-9,10${ }^{3} \mathrm{H}$ SSM was purified by preparative thin-layer chromatography of the reaction products three consecutive times in chloroform/methanol (95:5) and then twice in chloroform/methanol/acetic acid/water (50: $25: 8: 4)$. Greater than $95 \%$ of the $\left[N\right.$-palmitoyl- $\left.9,10-{ }^{3} \mathrm{H}\right] \mathrm{SM}$ was converted to $\left[N\right.$-palmitoyl-9, $\left.10-{ }^{3} \mathrm{H}\right]$ ceramide after treatment with $10 \mathrm{mU}$ SMase $/ \mathrm{ml}$ (B. cereus) for $1 \mathrm{~h}$ at $37^{\circ} \mathrm{C}$, as assayed by TLC, indicating a pure, functional substrate.

Lipoproteins. LDL (density, $1.020-1.063 \mathrm{~g} / \mathrm{ml}$ ) was isolated from fresh human plasma by preparative ultracentrifugation as previously described (19). Plasma LDL was labeled with [ $N$-palmitoyl-9,10$\left.{ }^{3} \mathrm{H}\right] \mathrm{SM}$ as follows: $\sim 3.5 \mathrm{mCi}(63 \mathrm{nmol})\left[N\right.$-palmitoyl-9,10- $\left.{ }^{3} \mathrm{H}\right] \mathrm{SM}$ and $13 \mathrm{nmol}$ phosphatidylcholine (PC) were mixed in chloroform, and the solvent was removed first under a stream of nitrogen and then by lyophilization. The dried lipids were resuspended in $1 \mathrm{ml}$ of $150 \mathrm{mM}$ $\mathrm{NaCl}, 1 \mathrm{mM}$ EDTA, $10 \mathrm{mM}$ Tris- $\mathrm{HCl}, \mathrm{pH} \mathrm{7.5,} \mathrm{and,} \mathrm{to} \mathrm{prepare}$ $\left[{ }^{3} \mathrm{H}\right] \mathrm{SM} / \mathrm{PC}$ liposomes, sonicated for three 50 -s pulses at $4^{\circ} \mathrm{C}$ using a tapered microtip on a sonicator (setting 3, model 450; Branson Ultrasonics Corp., Danbury, CT). The liposomes were then incubated with $30 \mathrm{mg}$ (by protein mass) of LDL, $50 \mathrm{~g}$ of partially purified phospholipid transfer protein, $100 \mathrm{U}$ penicillin, and $100 \mathrm{~g}$ streptomycin for $18 \mathrm{~h}$ at $37^{\circ} \mathrm{C}$ under argon. LDL was then separated from the liposomes after phospholipid transfer by centrifuging the mixture at $d=1.006 \mathrm{~g} /$ $\mathrm{ml}$ for $8 \mathrm{~h}$ at 35,000 rpm in a rotor (model 50.3; Beckman Instruments, Fullerton, CA); the supernate containing the liposomes was removed, and the LDL band at the bottom of the tube was harvested. The LDL solution was mixed with PBS and centrifuged as before. This wash procedure was performed four times, resulting in the removal of $95 \%$ of the unreacted $\left[{ }^{3} \mathrm{H}\right] \mathrm{SM} / \mathrm{PC}$ liposomes. All lipoproteins were stored under argon at $4^{\circ} \mathrm{C}$ and were used within 2 wk of preparation.

Control and SM-enriched LDL-lipid emulsions. Two aliquots of LDL (each $12 \mathrm{mg}$ by protein mass) were extracted by the method of Bligh and Dyer (20); $6 \mathrm{mg}$ of SM was added to the lipid extract of one of the aliquots. The solvent was then completely evaporated from these samples by exposure to a stream of nitrogen, followed by lyophilization. The dried lipids were resuspended in $6 \mathrm{ml}$ of PBS and sonicated under a stream of argon at $40^{\circ} \mathrm{C}$ until translucent $(90 \mathrm{~min}$ for the control emulsions and $130 \mathrm{~min}$ for the SM-enriched emulsions). The sonicated material was then centrifuged twice at $15,000 \mathrm{~g}$, and the supernate was harvested.

Ceramide and diacylglycerol assays. Ceramide and diacylglycerol were measured from aliquots of lipid extracts of LDL and emulsions using the method described by Schneider and Kennedy (21) and adapted by Preiss et al. (22). In this method, diacylglycerol (DAG) kinase phosphorylates ceramide and DAG using $\left[\gamma^{32} \mathrm{P}\right] \mathrm{ATP}$; the contents of ceramide and DAG in the experimental samples are calculated from amount of incorporated ${ }^{32} \mathrm{P}$ label in comparison with standard curves using known quantities of the two lipids. For ceramide measurements, the lipids were first incubated with $0.1 \mathrm{~N} \mathrm{KOH}$ in methanol for $1 \mathrm{~h}$ at $37^{\circ} \mathrm{C}$, which hydrolyzes DAG, but not ceramide. The extracted lipids were dried under nitrogen and then solubilized in $5 \mathrm{mM}$ cardiolipin, $7.5 \%$ octyl- $\beta$-glucopyranoside, and $1 \mathrm{mM}$ diethylenetriaminepentaacetic acid by bath sonication. This solution was then added to reaction buffer $(50 \mathrm{mM}$ imidazole- $\mathrm{HCl}, \mathrm{pH} 6.6,50 \mathrm{mM}$ $\mathrm{NaCl}, 12.5 \mathrm{mM} \mathrm{MgCl} 2,1 \mathrm{mM}$ EGTA) containing $s n$-1,2-DAG kinase $(0.7 \mathrm{U} / \mathrm{ml})$. The reaction was initiated by the addition of $\left[\gamma^{-32} \mathrm{P}\right]$ ATP (final concentration $=10 \mathrm{mM}$ ). After incubation at room temperature for $60 \mathrm{~min}$, the reaction was stopped by lipid extraction with chloroform/methanol/HCl (100:100:1, vol/vol/vol) and $10 \mathrm{mM}$ EDTA. Ceramide-1-phosphate and phosphatidic acid in the organic phase were separated by TLC using chloroform/methanol/acetic acid (65: $15: 5, \mathrm{vol} / \mathrm{vol} / \mathrm{vol}$ ); the lipids were visualized with autoradiography and identified by comparing with standards. The spots corresponding to these two lipids were scraped and counted, and the masses of the lipids were calculated by comparison with standard curves, as described above.

Sphingomyelin (SM), phosphatidylcholine (PC), and cholesterol assays. Lipid extracts (20) of LDL and emulsions were chromatographed by TLC using chloroform/methanol/acetic acid/ $\mathrm{H}_{2} \mathrm{O}(50: 25$ : $8: 4, \mathrm{vol} / \mathrm{vol} / \mathrm{vol} / \mathrm{vol})$. Individual phospholipid subclasses were visualized by iodine vapor staining, and the SM and PC spots were identified by comparison with standards. The spots were scraped, extracted twice with chloroform/methanol (2:1), and assayed for phosphate content by the method of Bartlett (23). Total cholesterol contents were assayed using an enzymatic colorimetric method (Cholesterol C kit; Wako Bioproducts, Richmond, VA); we verified that the values obtained by this method are similar to those obtained using gas-liquid chromatography (unpublished data).

Isolation of $L D L$ from human lesions. LDL was extracted from abdominal aortic aneurysm plaque material as previously described (4). Briefly, aortic plaque was removed from individuals as part of the standard reconstructive surgery for abdominal aortic aneurysms at the San Francisco Veterans Affairs Medical Center. Plaque material, which ranged in weight from 2-12 g, was obtained in the operating room and immediately placed into ice-cold $7-\mathrm{mM}$ citrate buffer, $\mathrm{pH}$ 7.4, containing $15 \mathrm{mM} \mathrm{NaCl}, 3 \mathrm{mM}$ EDTA, $0.5 \mathrm{mM}$ butylhydroxytoluene, $1 \mathrm{mM}$ phenylmethylsulfonylfluoride, $1.5 \mathrm{mg}$ aprotinin $/ \mathrm{ml}, 2$ $\mathrm{mM}$ benzamidine, and $0.08 \mathrm{mg}$ gentamycin sulfate $/ \mathrm{ml}$. Blood and adherent thrombus were removed by blotting with absorbent gauze, scrubbing with a small brush, and sharp dissection as necessary. Loosely retained lipoproteins were extracted by mincing the plaque into $0.5-1.0 \mathrm{~mm}^{2}$ pieces and incubating them overnight on an orbital shaker at $4^{\circ} \mathrm{C}$ in a nondenaturing buffer $(0.1 \mathrm{M}$ citrate, $\mathrm{pH} 7.4$, with 1 $\mathrm{mg}$ EDTA $/ \mathrm{ml}, 0.3 \mathrm{mg}$ benzamidine $/ \mathrm{ml}, 0.08 \mathrm{mg}$ gentamicin sulfate $/ \mathrm{ml}$, 
$10 \mu \mathrm{g}$ aprotinin/ml, $10 \mu \mathrm{g}$ Trolox $/ \mathrm{ml}$, (Trolox is an antioxidant), and $20 \mu \mathrm{g}$ phenylmethylsulfonyl fluoride/ml). The extracted material was cleared of particulate matter by centrifuging at $800 \mathrm{~g}$ for $10 \mathrm{~min}$, and $1.019<d<1.063-\mathrm{g} / \mathrm{ml}$ lipoproteins were isolated by sequential sodium bromide density ultracentrifugation $(4,19)$. To extract LDL from early human lesions, the same procedure was used, except the intima and inner media were peeled away from the outer media and adventitia before being minced and processed as above.

Apolipoprotein B-100 slot immunoblot analysis. The samples to be tested were applied to a nitrocellulose membrane using a slot blot apparatus. Next, the membrane was incubated with $5 \%$ Carnation nonfat dry milk in buffer A (24 mM Tris, $\mathrm{pH} 7.4$, containing $0.5 \mathrm{M}$ $\mathrm{NaCl}$ ) for $3 \mathrm{~h}$ at room temperature. The membrane was then incubated with rabbit anti-human apolipoprotein B-100 antiserum (1: 1,000 ) in buffer B (buffer A containing 0.1\% Tween-20, 3\% nonfat dry milk, and $0.1 \%$ bovine serum albumin) for $4 \mathrm{~h}$ at room temperature. After washing four times with buffer A containing $0.1 \%$ Tween- 20 , the blots were incubated with horseradish peroxidase-conjugated goat anti-rabbit $\operatorname{IgG}(1: 2,000)$ for $1 \mathrm{~h}$ in buffer B at room temperature. The membrane was subsequently washed twice with $0.3 \%$ Tween-20 in buffer A and twice with $0.1 \%$ Tween- 20 in buffer A. Finally, the blot was soaked in the enhanced chemiluminescence reagent for $2 \mathrm{~min}$ and exposed to $\mathrm{x}$-ray film for $1 \mathrm{~min}$. For Fig. 5, the relative intensities of the slot blot signals were determined by densitometirc scanning of the $\mathrm{x}$-ray film using a densitometer with Image-Quant software (see Fig. 5; computing densitometer, model 300A; Molecular Dynamics, Inc., Sunnyvale, CA).

Assay for LDL-SM hydrolysis by strips of rabbit aorta ex vivo. New Zealand white male rabbits $(2-3 \mathrm{~kg})$ were fed a chow diet containing $0.2 \%$ cholesterol and $10 \%$ soybean oil (wt/wt) for $18 \mathrm{~d}$. The animals were killed, and the thoracic aortae were removed rapidly and placed in a dissection dish with physiological Hanks' Trizma maleate buffer ( $133 \mathrm{mM} \mathrm{NaCl}, 3.6 \mathrm{mM} \mathrm{KCl}, 1.0 \mathrm{mM} \mathrm{CaCl}_{2}, 5.0 \mathrm{mM}$ Trizma maleate, and $16 \mathrm{mM}$ dextrose, $\mathrm{pH}$ 7.3). The aortae were then further dissected to remove excess fat and any clotted blood and then cut longitudinally and pinned, lumen side up, in a tissue culture dish. The aortic strips were washed several times with DMEM $/ 0.2 \%$ BSA and incubated at $37^{\circ} \mathrm{C}$ for $3.5 \mathrm{~h}$ in DMEM $/ 0.2 \%$ BSA containing $2 \mathrm{mg}$ $\left[{ }^{3} \mathrm{H}\right] \mathrm{SM}$-labeled LDL per ml. For certain experiments, the strips were preincubated at $37^{\circ} \mathrm{C}$ for $30 \mathrm{~min}$ in medium alone, or supplemented with $15 \mathrm{mM}$ EDTA or $200 \mu \mathrm{M}$ chloroquine. When present, these reagents were also added to the corresponding incubation media containing labeled LDL (see legend to Fig. 5). After the 3.5-h incubation of labeled LDL with aortic strips, media were removed (see below), the aortic strips were quickly washed twice in ice-cold PBS, and the center of the strip was cut away from the original cut ends. These center pieces were then minced and extracted in PBS, pH 7.4, containing $6 \mathrm{M}$ guanidine- $\mathrm{HCl}, 5 \mathrm{mM}$ EDTA, $0.02 \%$ sodium azide, $35 \mu \mathrm{M}$ leupeptin, $1.5 \mathrm{mg}$ aprotinin $/ \mathrm{ml}$, and $5 \mu \mathrm{M}$ pepstatin $\mathrm{A}$ for $36 \mathrm{~h}$ at $4^{\circ} \mathrm{C}$. The extract was centrifuged at $35,000 \mathrm{~g}$ for $30 \mathrm{~min}$, and lipids were extracted from the supernate by the method of Bligh and Dyer (20). $\left[{ }^{3} \mathrm{H}\right]$ Palmitate-SM, $\left[{ }^{3} \mathrm{H}\right]$ palmitate-ceramide, and free $\left[{ }^{3} \mathrm{H}\right]$ palmitate in the lipid extracts were separated by TLC using chloroform:methanol (95:5, vol/vol) or $n$-propanol:12.5\% ammonium hydroxide (80:20, vol/ vol). For controls, $\left[{ }^{3} \mathrm{H}\right] \mathrm{SM}-L D L$ that was incubated for $3.5 \mathrm{~h}$ in media without aortic strips, and $\left[{ }^{3} \mathrm{H}\right] \mathrm{SM}-\mathrm{LDL}$ that was incubated with the strips but not retained (i.e., in the media that was harvested after the incubation) were subjected to the same extraction procedures, including the 36-h incubation in guanidine buffer.

Iodination of EGF and assay for ${ }^{125}$ I-EGF degradation. Epidermal growth factor $(50 \mu \mathrm{g})$ was radioiodinated to a specific activity of 5,400 $\mathrm{cpm} / \mathrm{ng}$ (Iodobeads; Pierce Chemical Co., Rockford, IL) and was used within $48 \mathrm{~h}$ of labeling. After a 3.5-h incubation with aortic strips, in the absence or presence of $200 \mu \mathrm{M}$ chloroquine, degradation of ${ }^{125} \mathrm{I}$-EGF was assayed by the release of ${ }^{125} \mathrm{I}$-tyrosine (24).

Statistics. Unless otherwise indicated, results are given as means \pm $\mathrm{SD}(n=3)$; absent error bars in the figures signify SD values smaller than the graphic symbols.

\section{Results}

SMase-induced aggregation of $L D L$ in vitro requires active SMase enzyme and is mediated via high particle ceramide content. We first sought to determine whether active SMase enzyme is required for LDL aggregation or whether the effect is purely structural; for example, lipoprotein lipase-mediated bridging of LDL to cell-surface proteoglycans is a purely structural effect of the lipase molecule $(11,25)$. All of our previous studies in vitro utilized bacterial SMases, which are a reasonable model for mammalian SMases in regard to enzymatic activity but not necessarily in regard to structural actions. We began by carefully analyzing the time course of $B$. cereus SMase-induced LDL aggregation and LDL-SM hydrolysis. Whereas LDL-SM hydrolysis was $70 \%$ complete within the first 30 min of exposure to SMase (Fig. $1 \mathrm{~A}$, closed triangles), substantial LDL aggregation began to occur only after $30 \mathrm{~min}$ of incubation (Fig.
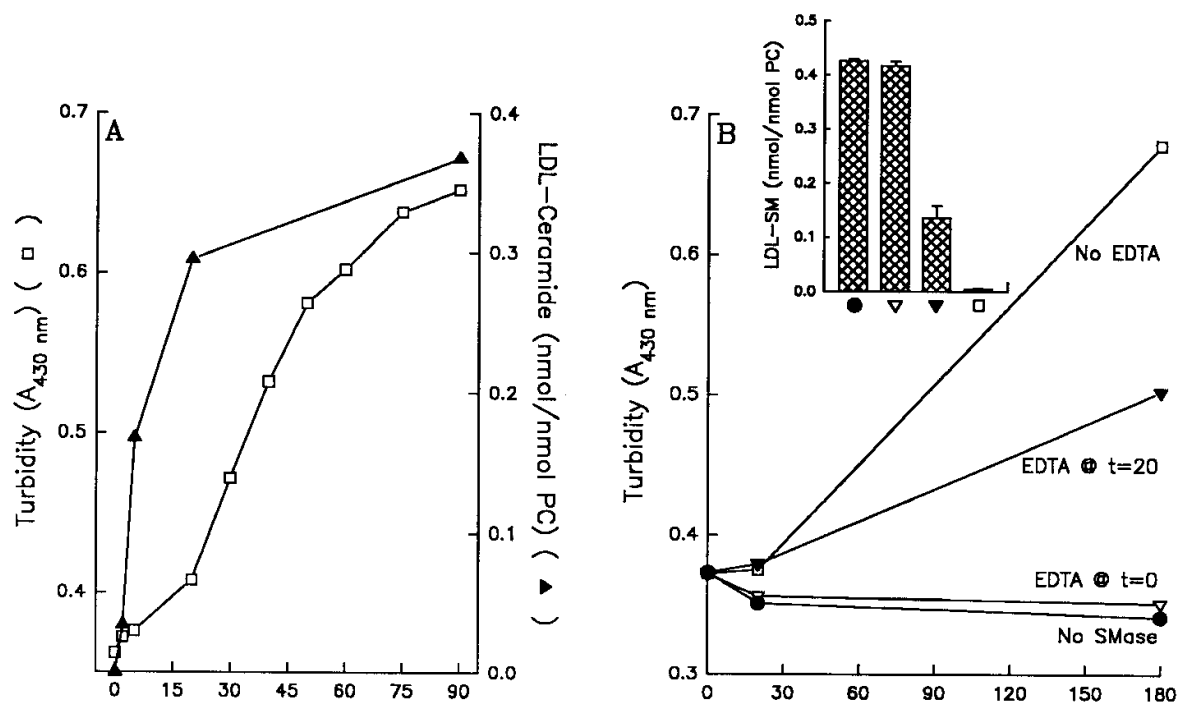

Time $(\mathrm{min})$
Figure 1. Kinetics of SM hydrolysis and LDL aggregation induced by SMase and the effects of enzymatic inhibition. $(A)$ LDL $(2 \mathrm{mg} / \mathrm{ml})$ was incubated with $50 \mathrm{mU}$ B. cereus $\mathrm{SMase} / \mathrm{ml}$ at $37^{\circ} \mathrm{C}$ in PBS containing $5 \mathrm{mM} \mathrm{MgCl}_{2}$. At the indicated time points, aliquots of the LDL were harvested then assayed for extent of SM hydrolysis (closed triangles) and for aggregation (open squares). (B) LDL was incubated in PBS containing $5 \mathrm{mM} \mathrm{MgCl}_{2}$ in the absence of SMase (filled circles), or in the presence of SMase without EDTA (open squares), with $25 \mathrm{mM}$ EDTA present from the start of the incubation (open triangles), or with $25 \mathrm{mM}$ EDTA added after $20 \mathrm{~min}$ of incubation (closed triangles). Samples were assayed for turbidity at the indicated timepoints. (Inset) Aliquots from the 180-min timepoint in $B$ were assayed for SM content. 


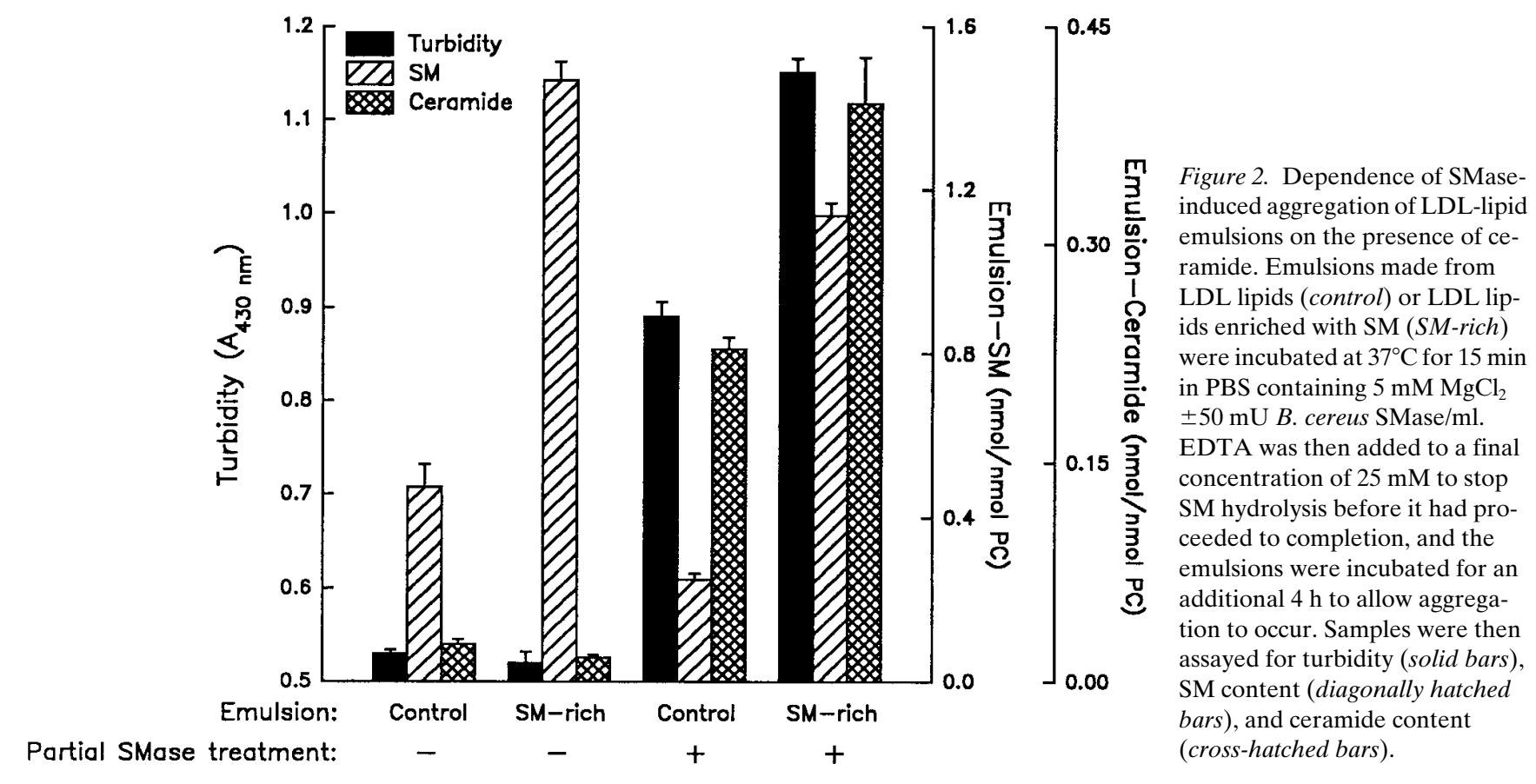

$1 B$,open squares). These kinetics are consistent with two possible mechanisms: a slow structural action of SMase, or a rapid enzymatic action that alters the particles so that they then slowly aggregate. To distinguish between these possibilities, we used EDTA to inhibit the enzymatic activity of the bacterial B. cereus SMase, which is a $\mathrm{Mg}^{2+}$-dependent enzyme (26). As in Fig. $1 A$, substantial aggregation of LDL occurred in the absence of EDTA after an initial lag period (Fig $1 \mathrm{~B}$, open squares). When EDTA was added at the beginning of the reaction, however, there was complete inhibition of LDL-SM hydrolysis (Fig. $1 \mathrm{~B}$, inset) and of LDL aggregation (Fig. $1 B$, open triangles). To show that EDTA is not a direct inhibitor of the aggregation process itself, EDTA was added $20 \mathrm{~min}$ after the SMase reaction had begun. As expected from the kinetic data described above, $68 \%$ of LDL-SM was hydrolyzed under these conditions (Fig. $1 \mathrm{~B}$, inset). Despite the presence of EDTA during the period of the aggregation process (i.e., after the 20-min incubation with SMase), substantial LDL aggregation still occurred (Fig. $1 \mathrm{~B}$, closed triangles). The degree of aggregation in this setting was consistent with the degree of LDL-SM hydrolysis under these conditions. Thus, EDTA can inhibit SMase-induced aggregation of LDL, but solely through its inhibition of SMase enzymatic activity, with no direct effects on the aggregation process itself. SMase that has been enzymatically inactivated by EDTA can no longer provoke LDL aggregation, indicating that enzymatic activity is an absolute requirement.

We next determined which of the three consequences of SMase enzymatic activity, namely, generation of choline-phosphate, generation of ceramide, and depletion of SM, is responsible for LDL aggregation. One of these possibilities, SM depletion, cannot be relevant to the pathogenesis of atherosclerosis: lesional LDL, which aggregates, is known to be enriched in SM compared to plasma LDL $(27,28)$. We began by incubating LDL with a 10-fold molar excess of choline-phosphate. This treatment failed to increase the turbidity of LDL (data

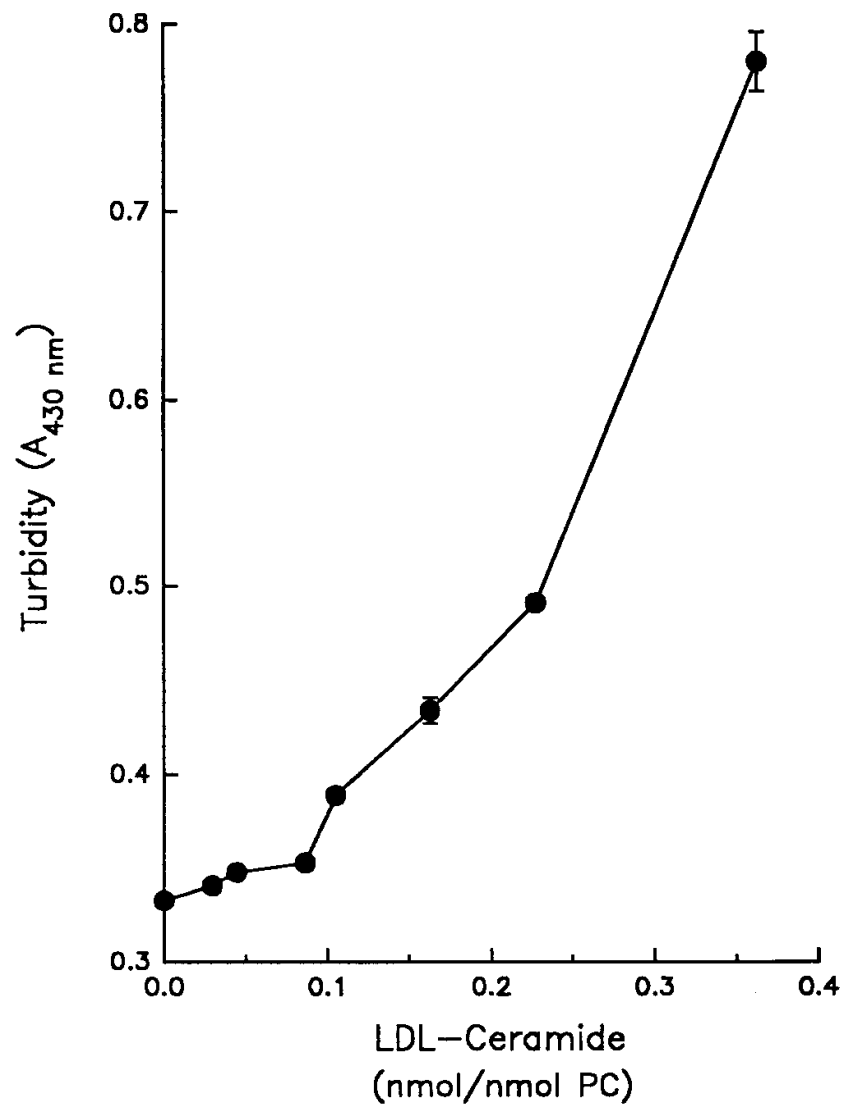

Figure 3. Relationship between LDL-ceramide content and LDL aggregation. LDL was incubated with $B$. cereus SMase as described in the legend to Fig. 1 for $0,1,3,5,7,10,12,15,20$, or $60 \mathrm{~min}$. At the end of the SMase incubation, $25 \mathrm{mM}$ EDTA was added to stop SM hydrolysis, and the samples were incubated further so that the total incubation time for all samples was $4 \mathrm{~h}$. Displayed are particle ceramide contents on the $x$-axis and aggregation (turbidity) on the $y$-axis. 
not shown), indicating that choline-phosphate does not mediate SMase-induced aggregation of LDL.

We then sought to distinguish whether aggregation results from an increase in LDL-ceramide or from a low LDL-SM content. Attempts to significantly alter SM and ceramide contents of intact LDL, for example by using phospholipid transfer protein or cholesteryl ester transfer protein, proved unsuccessful (see below). Therefore, we used LDL lipids to prepare protein-free synthetic emulsions, which we found in preliminary studies to aggregate like native LDL after SMase treatment. Emulsions were prepared with either LDL lipids (control emulsions) or LDL lipids to which we had added extra SM. Partial digestion of these emulsions with SMase was accomplished by adding EDTA to stop the reaction after only $15 \mathrm{~min}$ at $37^{\circ} \mathrm{C}$ (see above). As expected from our preliminary studies, the con- trol emulsion showed substantial particle aggregation (compare solid bars in first and third triplets of bars in Fig. 2). Partial enzymatic digestion of the SM-enriched emulsions generated ceramide-rich particles that still had a very high SM content (twofold greater than in undigested control emulsions). These ceramide-rich, SM-rich particles aggregated to an even greater degree than SMase-treated control emulsions (compare solid bars in third and fourth triplets of bars in Fig. 2), presumably because they had more ceramide than the control emulsions (see below). Thus, SMase-induced aggregation readily occurs even when the residual SM content of the particles is still very high, as it is in lesional $\operatorname{LDL}(27,28)$. SM depletion cannot explain SMase-induced aggregation. These results indicate that the increase in particle ceramide is the key factor in this process. To test this relationship directly using intact LDL, plasma
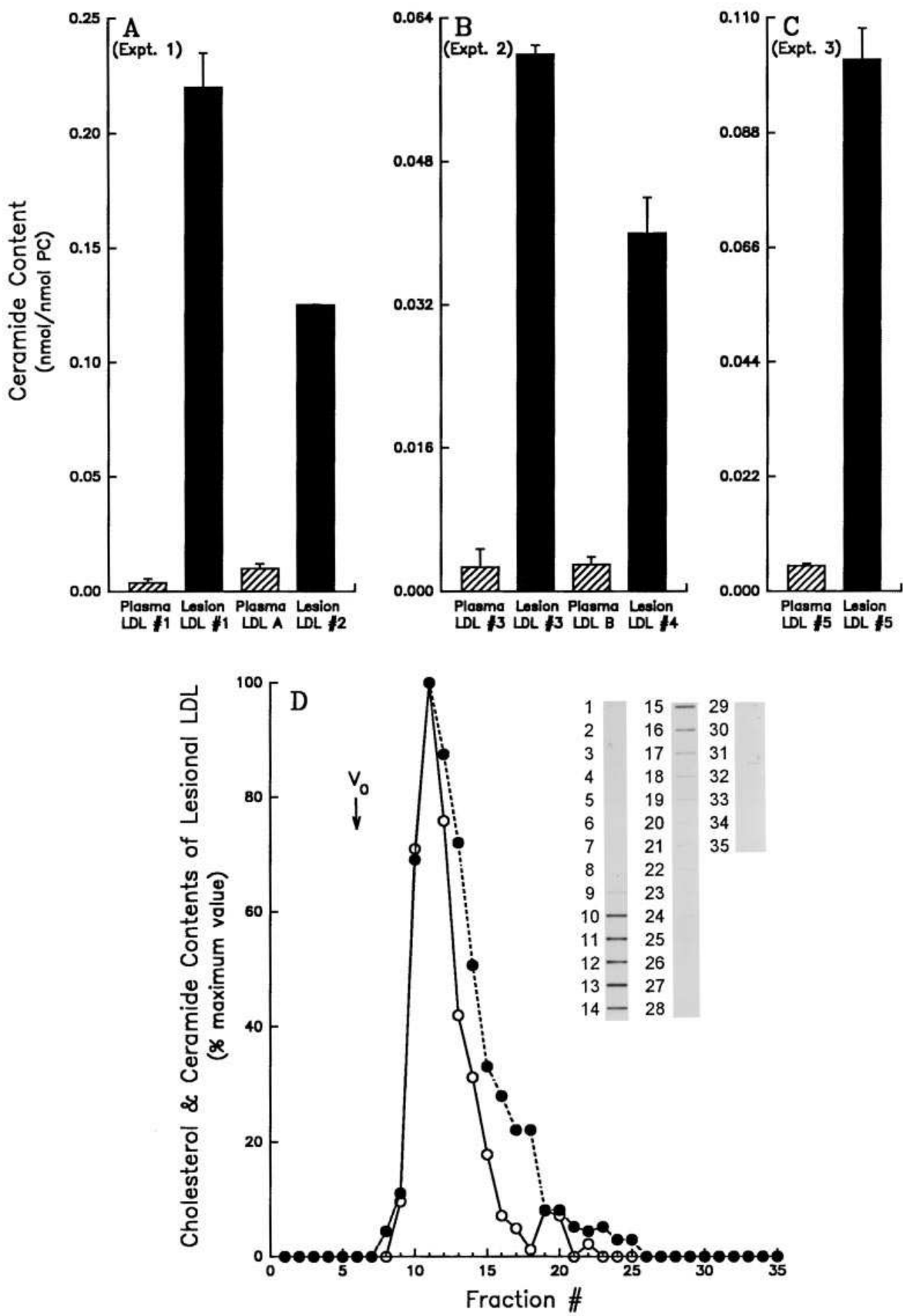

Figure 4. Ceramide content and gel-filtration chromatography of LDL extracted from human atherectomy specimens.

$(A-C)$ Three separate experiments, analyzing the ceramide contents of a total of five LDL preparations (lesion LDL 1-5) extracted from atherectomy material (solid bar). The ceramide contents of five samples of plasma LDL are also shown (diagonal-hatched bars); Plasma LDL 1, 3, and 5 are from the same patients as the samenumbered lesional LDL specimens. Plasma LDL $A$ and $B$ were isolated from the New York Blood Center and used for comparison of Lesion LDL 2 and 4, for which same-donor LDL was not available. Lipids were extracted from $40 \mu \mathrm{g}$ (by protein mass) of these samples and assayed for ceramide and $\mathrm{PC}$ content (data are expressed as nmol ceramide per nmol PC). When expressed as nmol ceramide per mg protein, the values for plasma LDL 1,3, and 5 were $5.1,4.5,3.7,1.6$, and 4.1 , and the values for lesion LDL 1-5 were 58, 51, 22, 32 , and 35 respectively. (C), $225 \mu \mathrm{g}$ (500 $\mu \mathrm{l})$ of lesion LDL 1 was dialyzed against 6 $\mathrm{M}$ guanidine- $\mathrm{HCl}, 10 \mathrm{mM}$ Tris- $\mathrm{HCl}, 5 \mathrm{mM}$ EDTA, pH 7.4 (buffer C) and loaded onto a Superose-6-HR 10/30 gel filtration column. The column was run in buffer $\mathrm{C}$ at a flow rate of $0.2 \mathrm{ml} / \mathrm{min}$ for $175 \mathrm{~min}$, yielding thirty-five 1-ml fractions. The void volume $\left(V_{\mathrm{o}}\right)$ was $6-7 \mathrm{ml}$. Aliquots from each fraction were assayed for content of cholesterol (closed circles) and ceramide (open circles) and for the presence of immunoreactive apolipoprotein B-100 using a slotimmunoblot procedure (inset). The cholesterol and ceramide data are expressed as percent maximum value (fraction 11), which was $28.2 \mathrm{nmol}$ cholesterol and 1.2 nmol ceramide per $\mathrm{ml}$. 
LDL was treated with SMase for varying times to generate particles with varying amounts of ceramide, allowed to aggregate, and then assayed for both aggregation and ceramide content. After an initial threshold level of $\sim 0.08 \mathrm{nmol}$ ceramide/ nmol phosphatidylcholine, there was a direct relationship between LDL-ceramide content and LDL aggregation (Fig. 3).

In summary, SMase-induced aggregation of LDL is mediated by enzymatic, not structural, actions of the SMase, and the key factor in causing aggregation is an increase in particle ceramide content, not a low absolute SM content. Both of these findings are consistent with the hypothesis that an arterial-wall SMase may contribute to the aggregation of lesional LDL. Note also that particle aggregation does not depend on apoB (see Discussion).

Human atheroma-derived LDL is enriched in ceramide. The finding that LDL-ceramide content is the key factor in SMase-induced aggregation prompted us to examine the ceramide content of human lesional LDL. For these experiments, material was obtained from two types of human lesions: atherectomy material (advanced atherosclerosis) and human aorta with only fatty streak involvement (early atherosclerosis). Tissue specimens were extracted overnight at $4^{\circ} \mathrm{C}$ in a non-denaturing aqueous buffer, and $1.019<d<1.063-\mathrm{g} / \mathrm{ml} \mathrm{li-}$ poproteins were isolated from the extraction buffer by sequential ultracentrifugation as previously reported (4).

Three separate experiments, analyzing the ceramide contents of lesional material from five different atherectomy samples altogether, are shown in Fig. $4 A-C$. Same-donor plasma LDL was available for comparison with Lesion LDL 1, 3, and 5; Lesion LDL 2 and 4 were compared with two different samples of plasma LDL prepared from plasma obtained from the New York City Blood Center (Plasma LDL A and Plasma $L D L B$ in Fig. 4). Remarkably, the samples of lesional LDL had a ceramide content that was 10-50-fold higher than that of plasma LDL, which was always ceramide poor. Further characterization of the lipids in lesional LDL by HPLC confirmed the presence of ceramide, with only trace amounts of the biosynthetic intermediate, dihydroceramide (29). To verify that our extraction procedure did not cause artifactual hydrolysis of LDL-SM, we showed that $\left[{ }^{3} \mathrm{H}\right] \mathrm{SM}$-labeled LDL added to ex-

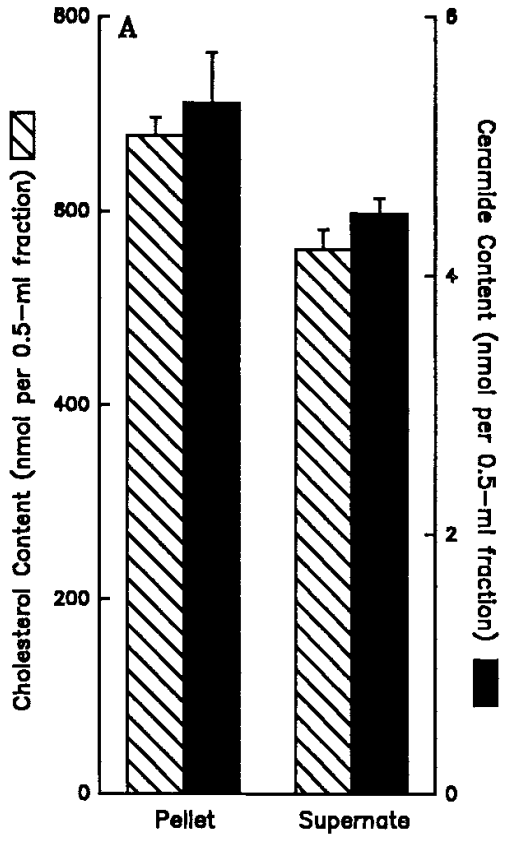

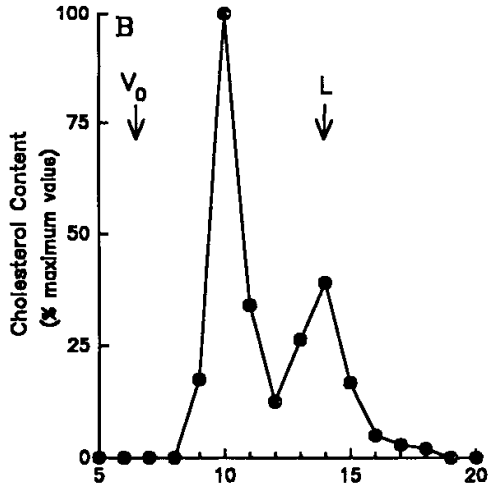
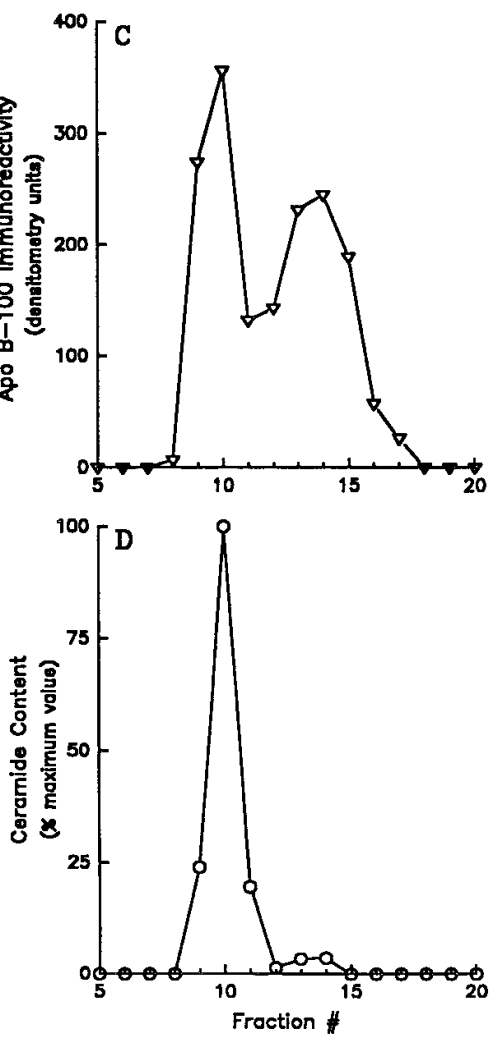

Figure 5. Ceramide is present only in aggregated forms of lesional LDL. (A) Lesion LDL 5 from Fig. 4 $(900 \mu \mathrm{g}$ protein in $500 \mu \mathrm{l}$ of Buffer D $[150 \mathrm{mM} \mathrm{NaCl}$, $10 \mathrm{mM}$ Tris-HCl, 2 mM EDTA, $\mathrm{pH}$ 7.4]) was centrifuged for $10 \mathrm{~min}$ at $23^{\circ} \mathrm{C}$ in an Eppendorf $5415 \mathrm{C}$ tabletop microcentrifuge at $10,000 \mathrm{~g}$. The pellet was washed twice by resuspension and recentrifugation in buffer $\mathrm{D}$. The final pellet (resuspended in $500 \mu \mathrm{l}$ of Buffer D) and the original supernate were assayed for total cholesterol (diagonal-hatched bars) and ceramide (solid bars) contents. When the same procedure was conducted with plasma LDL, all of the cholesterol was found in the supernate (not shown). $(B-D)$ the procedure described in $A$ was repeated with $750 \mu$ of lesional LDL; $500 \mu$ l of the supernatant fraction was loaded onto a Superose-6-HR 10/30 gel filtration column. The column was run in buffer $\mathrm{D}$, which contains no guanidine- $\mathrm{HCl}$ (Fig. 4), at a flow rate of $0.2 \mathrm{ml} / \mathrm{min}$; the void volume $\left(V_{\mathrm{o}}\right)$ was 6-7 $\mathrm{ml}$. Aliquots from each fraction were assayed for contents of total cholesterol $(B)$, immunoreactive apo B-100 using a slot-immunoblot procedure $(C)$, and ceramide $(D)$. The cholesterol and ceramide data are expressed as percent maximum value (fraction 10), which was $148.4 \mathrm{nmol}$ cholesterol and $3.5 \mathrm{nmol}$ ceramide per $\mathrm{ml}$; the apo B-100 slot immunoblot data are expressed as relative densitometric units. When plasma LDL was subjected to Superose-6 chromatography as above, all of the cholesterol and apo B-100 eluted in a sharp peak centered around fraction $14(L$ in $B)$. 
traction buffer with an unlabeled arterial sample was not hydrolyzed during extraction or sequential ultracentrifugation $(0.006 \pm 0.002 \%$ of the radioactivity in the original preparation of $\left[{ }^{3} \mathrm{H}\right] \mathrm{SM}-\mathrm{LDL}$ comigrated with ceramide on TLC, and this fraction remained exactly the same in $\left[{ }^{3} \mathrm{H}\right] \mathrm{SM}-\mathrm{LDL}$ subjected to the extraction procedure). To show that the ceramide was in LDL, Lesion LDL 1 was fractionated using a Superose- 6 gelfiltration column (molecular weight exclusion $=4 \times 10^{6}$ ), a commonly used chromatographic technique for separating lipoprotein classes. Note that the column was run in buffer containing $6 \mathrm{M}$ guanidine- $\mathrm{HCl}$ to partially dissociate large LDL aggregates (9, and below), which otherwise might not enter the column or elute in the void volume, and thus not be separated from lesional debris. As shown in Fig. $4 \mathrm{D}$, cholesterol, ceramide, and apolipoprotein B-100 (inset) coeluted within the included volume of the column. Finally, to determine if there had been generalized breakdown of phospholipids in LDL from advanced lesions, we assayed Lesion and Plasma LDL 3 for DAG, which is a product of phosphatidylcholine hydrolysis by phospholipase $\mathrm{C}$. Whereas the ceramide content of the lesional LDL was $54 \mathrm{pmol} / \mathrm{nmol} \mathrm{PC}$ (Fig. $4 \mathrm{~B}$ ), the DAG content of this material, as well as of the sample of plasma LDL, was below the detection limit of the assay $(<2 \mathrm{pmol} / \mathrm{nmol} \mathrm{PC})$. These data indicate specific hydrolysis of SM in lesional LDL and no evidence of a significant role for phospholipase $\mathrm{C}$ in vivo (14).

To examine LDL from early human lesions, we used the same extraction procedure to obtain LDL from a segment of aorta from a 43-yr/old male donor heart. Gross examination of this aortic segment revealed only fatty streaks, without any raised lesions. The ceramide content of the lesional LDL was $0.031 \pm 0.002 \mathrm{nmol} / \mathrm{nmol} \mathrm{PC}$, whereas same-donor plasma LDL had only $0.013 \pm 0.005 \mathrm{nmol}$ ceramide/nmol PC. Thus, even in relatively early atherosclerosis, lesional LDL is two- to threefold enriched in ceramide compared with plasma LDL.

Only aggregated lesional LDL is enriched in ceramide. Lesion LDL 5 from Fig. 4 was characterized for aggregation using centrifugation and gel-filtration chromatography, as described previously (30). As shown in Fig. $5 A, \sim 60 \%$ of the lesional LDL-cholesterol pelleted during a brief centrifugation (10 min at $10,000 \mathrm{~g}$ ), indicating the presence of apparently very large aggregates. This pelleted material contained ceramide (Fig. 5 $A$ ), consistent with a role for ceramide in LDL aggregation. To determine whether the ceramide in the $10,000 \mathrm{~g}$ supernate (Fig. $5 \mathrm{~A}$ ) was also associated with aggregates of LDL, this material was fractionated by gel-filtration chromatography using Superose 6 as in Fig. 4, but in the absence of guanidine- $\mathrm{HCl}$ (Fig. $5 B-D$ ). We calibrated the column with plasma LDL, which eluted in a sharp peak centered around fraction 14 based on cholesterol and apo B-100 immunoreactivity ( $L$ in Fig. 5 B). The data that the cholesterol (Fig. 5 B) and apo B-100 (Fig. $5 C$ ) of the $10,000 \mathrm{~g}$ supernate eluted in two peaks. The second peak, which contained $\sim 40 \%$ of the cholesterol and $50 \%$ of the apo B-100, eluted in the position of plasma LDL, indicating unaggregated material. The first peak eluted four fractions earlier, indicating aggregation. Essentially all of the ceramide was associated with the first peak of lesional LDL (Fig. 5 D). Thus, lesional LDL exists in three forms: apparently very large aggregates, smaller aggregates, and particles that behave like unaggregated LDL. Importantly, ceramide is present only in the aggregated forms of lesional LDL.

LDL-SM hydrolysis by the arterial wall. Enrichment of lesional LDL with ceramide could occur through two processes: hydrolysis of LDL-SM or transfer of preexisting ceramide from cells or cellular debris onto the LDL particles. To examine ceramide transfer, we attempted to enrich LDL in vitro by

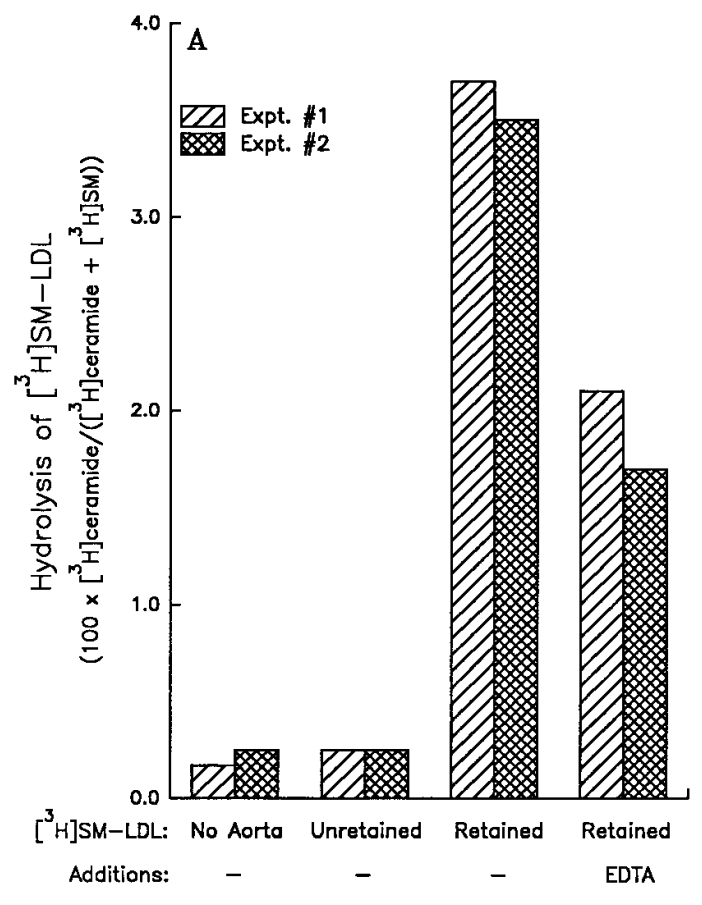

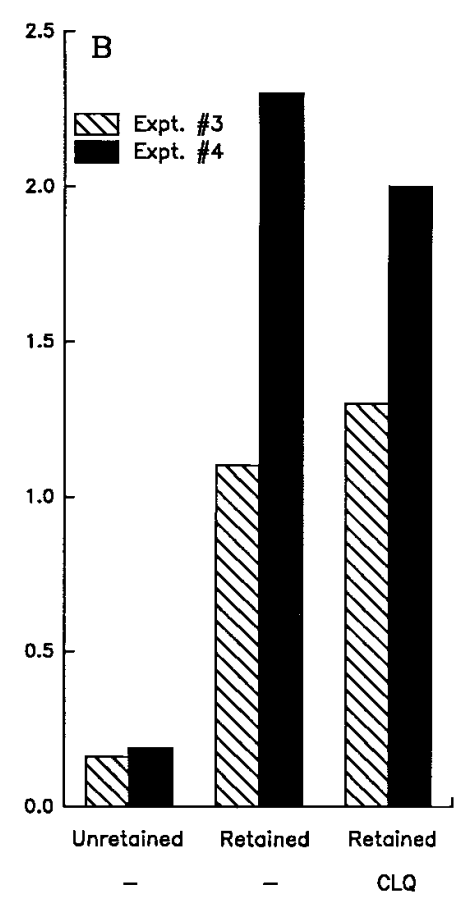

Figure 6. Hydrolysis of $\left[{ }^{3} \mathrm{H}\right] \mathrm{SM}-\mathrm{LDL}$ by strips of rabbit aorta. Aortae were isolated from rabbits fed a high-cholesterol diet for $18 \mathrm{~d}$ and incubated ex vivo for $3.5 \mathrm{~h}$ at $37^{\circ} \mathrm{C}$ with $2 \mathrm{mg}\left[{ }^{3} \mathrm{H}\right]$ palmitate-SM-labeled LDL per $\mathrm{ml} \mathrm{DMEM} / 0.2 \%$ BSA (usually $\sim 12$ $\mathrm{mg}$ total). Material extracted from these strips (Retained) was assayed for $\left[{ }^{3} \mathrm{H}\right] \mathrm{SM}$ and $\left[{ }^{3} \mathrm{H}\right]$ ceramide; $\sim 0.1 \%$ of the $\left[{ }^{3} \mathrm{H}\right] \mathrm{SM}$ LDL (10-20 $\mu \mathrm{g}$ LDL protein) was retained during the 3.5-h incubation period. These $\left[{ }^{3} \mathrm{H}\right]$ lipids were also assayed in $\left[{ }^{3} \mathrm{H}\right] \mathrm{SM}-$ LDL not exposed to aorta but incubated in extraction buffer (No Aorta) as well as in $\left[{ }^{3} \mathrm{H}\right] \mathrm{SM}-\mathrm{LDL}$ that was not retained by the aortic strips (i.e., still present in the medium after the 3.5-h incubation) and also incubated in extraction buffer (Unretained). For experiments 1 and $2(A)$, portions of the aortic strips were preincubated with DMEM/0.2\% BSA containing $15 \mathrm{mM}$ EDTA for $30 \mathrm{~min}$, and the 3.5-h incubation was also carried out in the presence of 15 mM EDTA. For experiments 3 and 4 (B), portions of the aortic strips were preincubated with DMEM/ $0.2 \%$ BSA containing $200 \mu \mathrm{M}$ chloroquine for $30 \mathrm{~min}$, and the 3.5-h incubation was also carried out in the presence of $200 \mu \mathrm{M}$ chloroquine. 
incubation with suspensions of ceramide or with sonicated emulsions containing ceramide. Even in the presence of phospholipid transfer protein or cholesteryl ester transfer protein, however, we were completely unable to incorporate preexisting ceramide into LDL. The only method we found to enrich LDL with ceramide in vitro was by digestion of the lipoprotein with SMase (Figs. 1, 2, and 3). These data indicate that ceramide transfers poorly, if at all, and that this mechanism is unlikely to explain the lipid composition of lesional LDL.

To directly examine LDL-SM hydrolysis in arteries, we incubated strips of rabbit aorta with $\left[{ }^{3} \mathrm{H}\right]$ palmitate-SM-labeled $\mathrm{LDL}$ for $3.5 \mathrm{~h}$ at $37^{\circ} \mathrm{C}$ and then extracted the retained LDL in guanidine buffer to look for evidence of $\left[{ }^{3} \mathrm{H}\right]$ ceramide generation (31). Histologic analysis of thin sections of the vessel strips after the 3.5-h incubation showed no cellular damage when compared to freshly fixed vessels (data not shown). The data from two separate experiments are shown in Fig. $6 \mathrm{~A}$. In both experiments, material extracted from the aortic strips had markedly increased $\left[{ }^{3} \mathrm{H}\right]$ ceramide compared with unretained $\left[{ }^{3} \mathrm{H}\right] \mathrm{SM}-\mathrm{LDL}$ or with $\left[{ }^{3} \mathrm{H}\right] \mathrm{SM}-\mathrm{LDL}$ incubated for $3.5 \mathrm{~h}$ in media without aortic strips (compare third pair of bars in Fig. $6 \mathrm{~A}$ with the first two pairs of bars). To determine whether the extraction procedure itself caused artifactual hydrolysis of LDL$\mathrm{SM}$, we performed this procedure using $\left[{ }^{3} \mathrm{H}\right] \mathrm{SM}-\mathrm{LDL}$ added to extraction buffer in the presence of minced pieces of aortic strips that had not been incubated previously with $\left[{ }^{3} \mathrm{H}\right] \mathrm{SM}-$ LDL. Under these conditions, there was no hydrolysis of $\left[{ }^{3} \mathrm{H}\right] \mathrm{SM}-\mathrm{LDL}$. Thus, the data in Fig. $6 \mathrm{~A}$ indicate hydrolysis of LDL-SM within the arterial wall.

At least four different SMases have been shown to be present in mammalian cells. Two of these are encoded by the acid SMase gene and arise by differential posttranslational processing (32). One of these acid SMase gene products is located in lysosomes (lysosomal SMase), does not require added cations, and is not inhibited by EDTA (33). The other SMase derived from the acid SMase gene is secreted by a wide variety of cell types (32) and requires exogenous $\mathrm{Zn}^{2+}$ for activity (32, $34)$. In addition, cells have a membrane-bound neutral SMase that requires $\mathrm{Mg}^{2+}$ for activity (35) as well as a cytoplasmic neutral SMase that is cation independent (36). Thus, two of the four known mammalian SMases require a divalent cation. To determine if aortic hydrolysis of LDL-SM requires divalent cations, portions of the aortic strips from the two experiments in Fig. $6 A$ were preincubated with $15 \mathrm{mM}$ EDTA and then incubated with the $\left[{ }^{3} \mathrm{H}\right] \mathrm{SM}-\mathrm{LDL}$ plus EDTA. As shown in the last doublet of bars in Fig. $6 \mathrm{~A}$, EDTA treatment decreased the generation of ceramide in the extracted material by $\sim 50 \%$. These data indicate that at least a portion of the arterial-wall SMase activity that hydrolyzes retained $\left[{ }^{3} \mathrm{H}\right] \mathrm{SM}-\mathrm{LDL}$ requires divalent cations.

Our overall hypothesis assumes that LDL-SM is hydrolyzed extracellularly, not intracellularly in lysosomes. The fact that a substantial portion of the arterial-wall SMase acting on retained LDL is inhibited by EDTA (Fig. $6 A$ ) indicates that much of the LDL-SM is not being hydrolyzed by lysosomal SMase, which is EDTA-resistant (see above). Furthermore, the $\left[{ }^{3} \mathrm{H}\right]$ palmitate-SM-labeled LDL that was retained in the aortic strips showed no enrichment in free $\left[{ }^{3} \mathrm{H}\right]$ palmitate, thereby suggesting no contact of the particle with lysosomal ceramidase (37). To further assess the contribution of lysosomes, we conducted a set of experiments in which $200 \mu \mathrm{M}$ chloroquine, an inhibitor of lysosomal hydrolases (38), was in- cluded in the aortic strip assay. We conducted two preliminary studies to validate this strategy. First, we incubated cultured human fibroblasts in the presence of $50 \mu \mathrm{M}$ chloroquine and found that cellular hydrolysis of $\left[{ }^{3} \mathrm{H}\right] \mathrm{SM}-\mathrm{LDL}$ was inhibited by $73 \%$ compared with that seen with untreated fibroblasts (data not shown); this finding indicates that chloroquine does indeed block the hydrolysis of LDL-SM by lysosomal SMase. Second, we assayed the ability of chloroquine to work in our aortic strip assay. For this study, we used ${ }^{125}$ I-labeled epidermal growth factor $\left({ }^{125} \mathrm{I}-\mathrm{EGF}\right)$, which is known to be internalized by receptor-mediated endocytosis and degraded in lysosomes in many cell types (39). Aortic strips were preincubated at $37^{\circ} \mathrm{C}$ for $30 \mathrm{~min}$ in medium without (control) or with $200 \mu \mathrm{M}$ chloroquine. ${ }^{125} \mathrm{I}-\mathrm{EGF}$ was added, then incubated with these strips for $3.5 \mathrm{~h}$. We found that chloroquine blocked the degradation of ${ }^{125}$ I-EGF by $50 \%$ (data not shown), indicating substantial inhibition of lysosomal hydrolases in the aortic strips. We next examined the effects of $200 \mu \mathrm{M}$ chloroquine on LDL-SM hydrolysis by aortic strips. As before, retained material, but not unretained $\left[{ }^{3} \mathrm{H}\right] \mathrm{SM}-\mathrm{LDL}$, was enriched in $\left[{ }^{3} \mathrm{H}\right]$ ceramide (Fig. $6 \mathrm{~B}$ : compare the first with the second pair of bars). When chloroquine was added in the same manner as in the ${ }^{125} \mathrm{I}$-EGF experiment, no substantial inhibition of $\left[{ }^{3} \mathrm{H}\right]$ ceramide enrichment of the retained material was seen (third pair of bars in panel $B$ ). In summary, these data indicate that SM delivered into the arterial wall on LDL is hydrolyzed by a nonlysosomal arterial SMase that is at least partially dependent on divalent cations.

\section{Discussion}

In light of our previous in vitro observation that SMase treatment of LDL leads to lipoprotein aggregation (15), an important atherogenic event (see Introduction, and 2, 9-11), the overall goal of the present study was to seek evidence for an arterial wall SMase acting on LDL retained in vivo. In this regard, we have shown that the mechanism of bacterial SMaseinduced aggregation of LDL in vitro is consistent with a similar process occurring with mammalian SMases in the subendothelium (Figs. 1-3), and we have provided direct evidence that an arterial-wall SMase activity hydrolyzes the SM of retained LDL (Figs. 4-6). Most remarkably, all the samples of lesional LDL that we examined were 10-50-fold enriched in ceramide compared with plasma LDL (Fig. 4). Although we have not proven that the ceramide in these samples is enough to cause aggregation (compare with Fig. 3), only the aggregated forms of lesional LDL are enriched in ceramide (Fig. 5). Moreover, one could easily imagine that other factors in lesions, such as proteoglycans, collagen, or lipoprotein lipase $(8,40,41)$, could lower the threshold for ceramide-induced LDL aggregation in vivo. In a similar manner, ceramide enrichment of LDL could lower the aggregation threshold for other possible inducers of aggregation, such as oxidation (16) or other lipases (14). It is also possible that the most ceramide-rich and aggregated lipoproteins would have already been rapidly ingested and degraded by lesional macrophages and thus would not have been present at the time of our extractions.

The mechanism and regulation of ceramide-induced aggregation represents an important area requiring further investigation. We speculate that the mechanism of aggregation may be related to the membrane-disruptive and possibly fusogenic properties of ceramide $(42,43)$ or to hydrogen bonding between ceramide and surface phospholipids of neighboring par- 
ticles (15). Clearly, the mechanism does not require apolipoproteins, since SMase induces aggregation of protein-free emulsions (Fig. 2), though the initial retention to arterial proteoglycans (40) or collagen (44) or the interaction with lipoprotein lipase (41) in vivo presumably does require apolipoprotein B. Moreover, other apolipoproteins, such as apolipoprotein AI, may prevent lipoprotein aggregation (45); in fact, we found that SMase-induced aggregation of LDL is completely blocked by free apo AI or apo AI-containing $\mathrm{HDL}_{3}$ when added to LDL at an apo AI:apo B-100 molar ratio of $0.5^{2}$. In this regard, the potent antiatherogenic effect of apo AI and $\mathrm{HDL}_{3}$ in humans (46) and in apo AI-transgenic mice (47, 48) may be partially mediated by inhibition of subendothelial lipoprotein aggregation.

Our current data indicate that at least a portion of the arterial-wall SMase activity is divalent cation-dependent (Fig. 6 $A$ ). As described in Results, two known mammalian SMases have this property: a membrane-bound, neutral, $\mathrm{Mg}^{2+}$-dependent SMase and a secreted $\mathrm{Zn}^{2+}$-dependent enzyme. In one report examining neuronal cells, the $\mathrm{Mg}^{2+}$-dependent SMase was shown to be externally oriented (49); a similar orientation on arterial wall cells could result in the hydrolysis of extracellularly retained lipoproteins. In preliminary data from our laboratory, we have shown that homogenates of nonlesional rabbit aortic intima have a neutral, $\mathrm{Mg}^{2+}$-dependent SMase activity (50) that can act on LDL-SM in vitro ${ }^{2}$, but we have no direct evidence thus far that this enzyme is in the proper orientation to hydrolyze LDL retained in the subendothelium in vivo. The $\mathrm{Zn}^{2+}$-dependent secreted SMase has been found by us to be secreted by several arterial wall cell types, including macrophages (32) and endothelial cells ${ }^{2}$. Although Zn-SMase has an acidic $\mathrm{pH}$ optimum using an SM-micelle substrate (32, 34 ), we found that this enzyme activity in macrophage-conditioned medium can hydrolyze LDL-SM at neutral $\mathrm{pH}$ in the presence of lipoprotein lipase ${ }^{2}$, an arterial wall enzyme known to be present in atherosclerotic lesions $(51,52)$. Based on these data, we speculate that the secreted Zn-dependent SMase, acting in cooperation with lipoprotein lipase, and perhaps externally oriented $\mathrm{Mg}^{2+}$-dependent SMase, may be important in subendothelial lipoprotein aggregation. The most direct test of these hypotheses will first require further molecular characterization of these and possibly other arterial-wall SMases, followed by inhibition of these activities in animal models by genetic or pharmacologic means.

Finally, the data in this report may have implications beyond the realm of subendothelial lipoprotein aggregation. Exposure of cells to SMase has been shown to induce inflammatory or apoptotic changes, both of which are known to occur in atherosclerosis (53-55), via ceramide-induced signaling pathways $(56,57)$. Furthermore, treatment of macrophages with SMase increases the potency of atherogenic lipoproteins to stimulate the cholesterol esterification pathway (58). Thus, the same SMase activity that we have now shown hydrolyzes extracellular, retained LDL-SM might also hydrolyze cellular SM, which is known to be concentrated in the external leaflet of the plasma membrane (29). Furthermore, it is possible that when cells, particularly macrophages, ingest large amounts of ceramide-rich lesional LDL, some of the ceramide escapes lysosomal hydrolysis and enters the signalling pathway. As with the

2. Schissel, S.L., Williams, K.J., and Tabas, I., unpublished data. aggregation hypothesis, these ideas will be best tested by using experimental systems with altered arterial wall SMase activity.

\section{Acknowledgments}

We thank Dr. Alfred H. Merrill, Department of Biochemistry at Emory University School of Medicine, Atlanta, GA, for conducting the high-performance liquid chromatographic analysis of ceramide extracted from lesional LDL; Dr. Henry Hoff, Cleveland Clinic Foundation, Cleveland, $\mathrm{OH}$, for providing human lesional extracts for pilot studies; Drs. Xian Chen Jiang and Alan Tall, Columbia University, New York, for providing phospholipid transfer protein; and Dr. Henry Ginsberg for providing anti-apolipoprotein B-100 antiserum; and Drs. Kelechi Lawrence and Donald Landry for assisting with the synthesis of ${ }^{3} \mathrm{H}$-sphingomyelin.

This study was supported by National Institutes of Health grants HL-39703 (I. Tabas), HL-21006 (I. Tabas), and HL-38956 (K.J. Williams); a cardiovascular research grant from the W.W. Smith Charitable Trust (K.J. Williams); an Established Investigator award from the American Heart Association and Genentech (K.J. Williams); and the Research Service, Veterans Affairs (J.H. Rapp). S.L. Schissel was supported by National Institutes of Health Medical Scientist Training grant 5T32-GM07367, and G. Graham was supported by a National Institutes of Health medical student summer research grant $(5 \mathrm{~T} 35 \mathrm{HL}-$ 07616).

\section{References}

1. Schwenke, D.C., and T.E. Carew. 1989. Initiation of atherosclerotic lesions in cholesterol-fed rabbits: I. Focal increases in arterial LDL concentrations precede development of fatty streak lesions. Arteriosclerosis. 9:895-907.

2. Nievelstein, P.F.E.M., A.M. Fogelman, G. Mottino, and J.S. Frank. 1991. Lipid accumulation in rabbit aortic intima 2 hours after bolus infusion of low density lipoprotein. Arterioscler. Thromb. 11:1795-1805.

3. Kreuzer, J., M.B. Lloyd, D. Bok, G.M. Fless, A.M. Scanu, A.J. Lusis, and M.E. Haberland. 1994. Lipoprotein(a) displays increased accumulation compared with low-density lipoprotein in the murine arterial wall. Chem. Phys. Lipids. 67/68:175-190.

4. Rapp, J.H., A. Lespine, R.L. Hamilton, N. Colyvas, A.H. Chaumeton, J. Tweedie-Hardman, L. Kotite, S.T. Kunitake, R.J. Havel, and J.P. Kane. 1994. Triglyceride-rich lipoproteins isolated by selected-affinity anti-apolipoprotein B immunosorption from human atherosclerotic plaque. Arterioscler. Thromb. 14:1767-1774.

5. Schwenke, D.C., and T.E. Carew. 1989. Initiation of atherosclerotic lesions in cholesterol-fed rabbits. II. Selective retention of LDL vs. selective increases in LDL permeability in susceptible sites of arteries. Arteriosclerosis. 9: 908-918.

6. Steinberg, D., S. Parthasarathy, T.E. Carew, J.C. Khoo, and J.L. Witztum. 1989. Beyond cholesterol: modifications of low-density lipoprotein that increase its atherogenicity. N. Engl. J. Med. 320:915-924.

7. Ross, R. 1995. Cell biology of atherosclerosis. Annu. Rev. Physiol. 57: 791-804.

8. Williams, K.J., and I. Tabas. 1995. The response-to-retention hypothesis of early atherogenesis. Arterioscler. Thromb. Vasc. Biol. 15:551-561.

9. Hoff, H.F., and R.E. Morton. 1985. Lipoproteins containing apo B extracted from human aortas: structure and function. Ann. NY Acad. Sci. 454: 183-194.

10. Guyton, J.R., and K.F. Klemp. 1996. Development of the lipid-rich core in human atherosclerosis. J. Lipid Res. 16:4-11.

11. Tabas, I., Y. Li, R.W. Brocia, S.W. Wu, T.L. Swenson, and K.J. Williams. 1993. Lipoprotein lipase and sphingomyelinase synergistically enhance the association of atherogenic lipoproteins with smooth muscle cells and extracellular matrix. A possible mechanism for low density lipoprotein and lipoprotein(a) retention and macrophage foam cell formation. J. Biol. Chem. 268: 20419-20432.

12. Hoff, H.F., J. O'Neill, J.M. Pepin, and T.B. Cole. 1990. Macrophage uptake of cholesterol-containing particles derived from LDL and isolated from atherosclerotic lesions. Eur. Heart J. 11:105-115.

13. Khoo, J.C., E. Miller, P. McLoughlin, and D. Steinberg. 1988. Enhanced macrophage uptake of low density lipoprotein after self-aggregation. Arteriosclerosis. 8:348-358.

14. Suits, A.G., A. Chait, M. Aviram, and J.W. Heinecke. 1989. Phagocytosis of aggregated lipoprotein by macrophages: low density lipoprotein receptordependent foam-cell formation. Proc. Natl. Acad. Sci. USA. 86:2713-2717.

15. Xu, X., and I. Tabas. 1991. Sphingomyelinase enhances low density lipo- 
protein uptake and ability to induce cholesteryl ester accumulation in macrophages. J. Biol. Chem. 266:24849-24858.

16. Hoff, H.F., J. O’Neill, G.M. Chisolm III, T.B. Cole, O. Quehenberger, H. Esterbauer, and G. Jürgens. 1989. Modification of low density lipoprotein with 4-hydroxynonenal induces uptake by macrophages. Arteriosclerosis. 9: $538-549$.

17. Sripada, P.K., P.R. Maulik, J.A. Hamilton, and G.G. Shipley. 1987. Partial synthesis and properties of a series of $N$-acylsphingomyelins. J. Lipid Res. 28:710-718.

18. Ahmad, T.Y., J.T. Sparrow, and J.D. Morrisett. 1985. Fluorine-, pyreneand nitroxide-labeled sphingomyelin: semisynthesis and thermotropic properties. J. Lipid Res. 26:1160-1165.

19. Havel, R.J., H. Eder, and J. Bragdon. 1955. The distribution and chemical composition of ultracentrifugally reported lipoproteins in human serum. $J$. Clin. Invest. 34:1345-1353.

20. Bligh, E.G., and W.J. Dyer. 1959. A rapid method for total lipid extraction and purification. Can. J. Biochem. Physiol. 37:911-917.

21. Schneider, E.G., and E.P. Kennedy. 1976. Partial purification and properties of diglyceride kinase from Escherichia coli. Biochim. Biophys. Acta. 441: 201-212.

22. Preiss, J., C.R. Loomis, W.R. Bishop, R. Stein, J.E. Niedel, and R.M. Bell. 1986. Quantitative measurement of sn-1,2-diacylglycerols present in platelets, hepatocytes, and ras- and sis-transformed normal rat kidney cells. J. Biol. Chem. 261:8597-8600.

23. Bartlett, G.R. 1959. Phosphorus assay in column chromatography. $J$. Biol. Chem. 234:466-468.

24. Goldstein, J.L., S.K. Basu, and M.S. Brown. 1983. Receptor-mediated endocytosis of low density lipoprotein in cultured cells. Methods Enzymol. 98: 241-260.

25. Williams, K.J., G.M. Fless, K.A. Petrie, M.L. Snyder, R.W. Brocia, and T.L. Swenson. 1992. Mechanisms by which lipoprotein lipase alters cellular metabolism of lipoprotein(a), low density lipoprotein, and nascent lipoproteins. Roles for low density lipoprotein receptors and heparan sulfate proteoglycans. J. Biol. Chem. 267:13284-13292.

26. Ikezawa, H., M. Matsushita, M. Tomita, and R. Taguchi. 1986. Effects of metal ions on sphingomyelinase activity of Bacillus cereus. Arch. Biochem. Biophys. 249:588-595.

27. Hoff, H.F. 1983. LDL in the arterial wall: Localization, quantitation, and characterization. In Handbook of Electrophoresis. Vol. III. Lipoprotein Methodology and Human Studies. L.A. Lewis, editor. CRC Press, Boca Raton, FL. 133-165

28. Ylä-Herttuala, S., W. Palinski, M.E. Rosenfeld, S. Parthasarathy, T.E. Carew, S. Butler, J.L. Witztum, and D. Steinberg. 1989. Evidence for the presence of oxidatively modified low density lipoprotein in atherosclerotic lesions of rabbit and man. J. Clin. Invest. 84:1086-1095.

29. Merrill, A.H., and D.D. Jones. 1990. An update of the enzymology and regulation of sphingomyelin metabolism. Biochim. Biophys. Acta. 1044:1-12.

30. Lougheed, M., and U.P. Steinbrecher. 1996. Mechanism of uptake of copper-oxidized low denisty lipoprotein in macrophages is dependent on its extent of oxidation. J. Biol. Chem. 271:11798-11805.

31. Nievelstein-Post, P., G. Mottino, A. Fogelman, and J. Frank. 1994. An ultrastructural study of lipoprotein accumulation in cardiac valves of the rabbit. Arterioscler. Thromb. 14:1151-1161.

32. Schissel, S.L., E.H. Schuchman, K.J. Williams, and I. Tabas. $1996 . \mathrm{Zn}^{2+}$ stimulated sphingomyelinase is secreted by many cell types and is a product of the acid sphingomyelinase gene. J. Biol. Chem. 271:18431-18436.

33. Spence, M.W. 1993. Sphingomyelinases. Adv. Lipid Res. 26:3-23.

34. Spence, M.W., D.M. Byers, F.B. St.C.Palmer, and H. W. Cook. 1989. A new $\mathrm{Zn}^{2+}$-stimulated sphingomyelinase in fetal bovine serum. J. Biol. Chem. 264:5358-5363.

35. Chatterjee, S. 1993. Neutral sphingomyelinase. Adv. Lipid Res. 26:2548.

36. Okazaki, T., A. Bielawska, N. Domae, R.M. Bell, and Y.A. Hannun. 1994. Characteristics and partial purification of a novel cytosolic, magnesiumindependent, neutral sphingomyelinase activated in the early signal transduction of 1a,25-dihydroxyvitamin $\mathrm{D}_{3}$-induced HL-60 cell differentiation. J. Biol.
Chem. 269:4070-4077.

37. Bernardo, K., R. Hurwitz, T. Zenk, R.J. Desnick, K. Ferlinz, E.H. Schuchman, and K. Sandhoff. 1995. Purification, characterization, and biosynthesis of human acid ceramidase. J. Biol. Chem. 270:11098-11102.

38. Goldstein, J.L., and M.S. Brown. 1977. The low-density lipoprotein pathway and its relation to atherosclerosis. Annu. Rev. Biochem. 46:897-930.

39. Goldstein, J.L., M.S. Brown, R.G.W. Anderson, D.W. Russell, and W.J. Schneider. 1985. Receptor-mediated endocytosis: concepts emerging from the LDL receptor system. Annu. Rev. Cell Biol. 1:1-39.

40. Camejo, G., E. Hurt-Camejo, U. Olsson, and G. Bondjers. 1993. Proteoglycans and lipoproteins in atherosclerosis. Curr. Opin. Lipidol. 4:385-391.

41. Goldberg, I.J. 1996. Lipoprotein lipase and lipolysis: central roles in lipoprotein metabolism and atherogenesis. J. Lipid Res. 37:693-707.

42. van Meer, G. 1993. Transport and sorting of membrane lipids. Curr Opin. Cell Biol. 5:661-673.

43. Skiba, P.J., X. Zha, S.L. Schissel, F.R. Maxfield, and I. Tabas. 1996. The distal pathway of lipoprotein-induced cholesterol esterification, but not sphingomyelinase-induced cholesterol esterification, is energy-dependent. J. Biol. Chem. 271:13392-13400.

44. Bowness, J.M., A.H. Tarr, and R.I. Wiebe. 1989. Transglutaminase-catalysed cross-linking: a potential mechanism for the interaction of fibrinogen, low density lipoprotein and arterial type III procollagen. Thromb. Res. 54:357367.

45. Khoo, J.C., E. Miller, P. McLoughlin, and D. Steinberg. 1990. Prevention of low density lipoprotein aggregation by high density lipoprotein or apolipoprotein A-I. J. Lipid Res. 31:645-652.

46. Tall, A.R. 1990. Plasma high density lipoproteins. Metabolism and relationship to atherogenesis. J. Clin. Invest. 86:379-384.

47. Rubin, E.M., R.M. Krauss, E.A. Spangler, J.G. Verstuyft, and S.M Clift. 1991. Inhibition of early atherogenesis in transgenic mice by human apolipoprotein AI. Nature (Lond.). 353:265-267.

48. Plump, A.S., C.J. Scott, and J.L. Breslow. 1994. Human apolipoprotein A-I gene expression raises HDL and suppresses atherosclerosis in the apo E-deficient mouse. Proc. Natl. Acad. Sci. USA. 91:9607-9611.

49. Mohan Das, D.V., H.W. Cook, and M.W. Spence. 1984. Evidence that neutral sphingomyelinase of cultured murine neuroblastoma cells is oriented externally on the plasma membrane. Biochim. Biophys. Acta. 777:339-342.

50. Spence, M.W., J.K. Burgess, and E.R. Sperker. 1979. Neutral and acid sphingomyelinases: somatotopographical distribution in human brain and distribution in rat organs. A possible relationship with the dopamine system. Brain Res. 168:543-551.

51. Ylä-Herttuala, S., B.A. Lipton, M.E. Rosenfeld, I.J. Goldberg, D. Steinberg, and J.L. Witztum. 1991. Macrophages and smooth muscle cells express lipoprotein lipase in human and rabbit atherosclerotic lesions. Proc. Natl. Acad. Sci. USA. 88:10143-10147.

52. Jonasson, L., G. Bondjers, and G.K. Hansson. 1987. Lipoprotein lipase in atherosclerosis: its presence in smooth muscle cells and absence from macrophages. J. Lipid Res. 28:437-445.

53. Libby, P., and G.K. Hansson. 1991. Involvement of the immune system in human atherogenesis: current knowledge and unanswered questions. $L a b$. Invest. 64:5-15.

54. Geng, Y., and P. Libby. 1995. Evidence for apoptosis in advanced human atheroma. Colocalization with interleukin-1b-converting enzyme. Am. J. Pathol. 147:251-266.

55. Han, D.K.M., C.C. Haudenschild, M.K. Hong, B.T. Tinkle, M.B. Leon, and G. Liau. 1995. Evidence for apoptosis in human atherogenesis and in a rat vascular injury model. Am. J. Pathol. 147:267-277.

56. Kolesnick, R.N. 1991. Sphingomyelin and derivatives as cellular signals Prog. Lipid Res. 30:1-38.

57. Hannun, Y.A., and R.M. Bell. 1989. Functions of sphingolipids and sphingolipid breakdown products in cellular regulation. Science (Wash. DC). 243: 500-507.

58. Okwu, A.K., X. Xu, Y. Shiratori, and I. Tabas. 1994. Regulation of the threshold for lipoprotein-induced acyl-CoA:cholesterol $O$-acyltransferase stimulation in macrophages by cellular sphingomyelin content. J. Lipid Res. 35:644655 . 